\section{INDIVIDUO Y CIUDADANO: LA CUESTIÓN DEL SUJETO EN LA DEMOCRACIA EN AMÉRICA DE A. DE TOCQUEVILLE}

\author{
Juan Manuel Ros Cherta \\ Dpto de Filosofía y Sociología. Facultad de CC. Humanas y Sociales \\ Universidad "Jaume I" de Castellón. \\ Avda. Sos Baynat s/n E-12071 Castellón. \\ rosc@fis.uji.es
}

\begin{abstract}
Prevailing interpretations asume that the main issue dealt with by Tocqueville in Democracy in America is that of the tension between Equality and Freedom. The present article suggests that there is another much more important issue, which has been frequently ignored: that of the democratic subject. In dealing with this, Tocqueville criticizes the ilusions of individualism and drafts the main lines of a "democratic anthroponomy".
\end{abstract}

KEY WORDS: democracy; individualism; subject; citizen; anthroponomy.

\section{INTRODUCCIÓN}

Toda la filosofía política de Tocqueville gira en torno al tema de la democracia. Su primer gran escrito -La Democracia en América- muestra ya claramente las principales cuestiones que dominan el curso de su reflexión. El ejemplo de la sociedad norteamericana y la comparación de ésta con Europa -Francia e Inglaterra, fundamentalmente- le sirven para analizar, en la primera parte de la obra (1835), las instituciones políticas de la democracia moderna. La segunda parte (1840), más abstracta y propiamente filosófica que la anterior, está dedicada al estudio de los efectos de la democracia sobre las ideas, los sentimientos, las costumbres $y$, en definitiva, sobre las relaciones entre la sociedad civil y la sociedad política.

Como es sabido, la primera parte de la citada obra -más descriptiva y sociológicamente centrada en Norteamérica que la segunda- obtuvo un éxito tal que llevó a los más prestigiosos medios intelectuales de la época a calificar a nuestro autor como un nuevo Montesquieu. En contrapartida, la segunda parte fue recibida, salvo notables

\section{INDIVIDUAL AND CITIZEN: THE QUESTION OF THE SUBJECT IN THE TOCQUEVILLE'S DEMOCRACY IN AMERICA}

RESUMEN: En las interpretaciones más relevantes se asume que el asunto principal que trata Tocqueville en La Democracia en América es el de la tensión entre igualdad y libertad. El presente artículo sugiere que hay otro tema más importante y con frecuencia ignorado: a saber, el del sujeto democrático. Tocqueville aborda la cuestión criticando las ilusiones del individualismo y esbozando las líneas maestras de una antroponomía democrática.

PALABRAS CLAVE: democracia; individualismo; sujeto; ciudadano; antroponomía.

excepciones ${ }^{1}$, con mucho menos entusiasmo y con una tónica general de crítica ante lo que se consideraba como su defecto principal: a saber, excesiva teorización y falta de base empirica (Jardin, 1988, 202). Al parecer, Tocqueville se encontró con un público poco preparado para apreciar, en su justa medida, la originalidad metodológica (Sauca, 1995) y la clarividente meditación filosófica sobre la democracia moderna que contiene $e^{2}$. A este respecto, cabe señalar que el movimiento de recuperación de nuestro autor, al que asistimos desde la segunda mitad del pasado siglo, se debe, a mi juicio, al reconocimiento del valor profundamente instructivo de esta parte de la obra para la teoria de la democracia. En esta dirección, el presente artículo trata de profundizar en uno de los principales aspectos normativos de índole ético-filosófica que se encuentran en la mencionada obra como lo es, en efecto, la cuestión del sujeto democrático.

Las interpretaciones al uso tienden a considerar que el problema fundamental tratado por Tocqueville en La Democracia en América es el de la tensión entre la igualdad y la libertad ${ }^{3}$. Dicho problema suele formularse en términos 
más o menos parecidos a éste: ¿cómo puede salvaguardarse la libertad en una sociedad, como la democráticomoderna, progresivamente dominada por el ideal igualitario? Se trata, ciertamente, de un problema básico en el pensamiento de nuestro autor. No obstante, hay otro lógicamente anterior y sobre el que, a mi juicio, no se ha llamado suficientemente la atención. Nos referimos al de la relación entre la individualidad y la sociabilidad, esto es, lo que podríamos denominar, en clave de filosofía práctica, como el problema del sujeto democrático. En este sentido, podemos interpretar que el principal problema que se plantea Tocqueville a lo largo de La Democracia en América -y especialmente en su segunda parte- es el de la conformación del hombre por la democracia y de ahí su interés en analizar minuciosamente la naturaleza, las consecuencias, los inconvenientes y los posibles remedios a dicha transformación. No se trata, como se ha dicho muchas veces, de una mera descripción sociológica, sino de una respuesta crítica a la forma en la que la democracia afecta a la relación entre el individuo y el ciudadano (Hennis, 1991). De manera que lo que preocupa esencialmente a nuestro autor son las tendencias individualistas que observa en la sociedad democrática moderna y los peligros que de ello se derivan, a saber, la degradación del ser humano en el aislamiento egoísta y las nuevas formas de servidumbre que le acompañan. Desde esta óptica, pues, la cuestión central que motiva la reflexión de Tocqueville sobre la democracia podría formularse así: ¿cómo preservar la integridad individual del ser humano y recuperar, al mismo tiempo, al ciudadano comprometido con la vida pública en una democracia moderna? Para responder a dicho interrogante, nuestro autor nos ofrece una auténtica radiografía del homo democraticus que, en la forma de una crítica al individualismo, contiene, como veremos a continuación, los trazos principales de una antroponomía democrática.

\section{LAS ILUSIONES DEL INDIVIDUALISMO Y SUS POSIBLES REMEDIOS}

Tocqueville es, ciertamente, uno de los primeros en emplear el término "individualismo" en la literatura política de la época (Lamberti, 1970, 13; Renaut, 1993, 81) y lo hace de una forma ciertamente original puesto que su interpretación se distancia tanto de quienes lo refieren como una causa de los males de la era moderna, como de aquéllos que lo ensalzan invocando la imagen de la libertad, sobre todo económica. En efecto, frente a la idea del origen revolucionario del individualismo y sus efectos negativos sobre el orden social -ya sea tradicional (restauracionistas) o futuro (saintsimonianos)-, el aristócrata normando concibe a aquél como un producto democrático y no-revolucionario e insiste, a partir de ahí, en que no debe confundirse el valor de la autonomía individual con el individualismo. Por otra parte, frente a la afirmación de los derechos individuales y de las virtudes de la cultura capitalista que defienden los liberales políticos o económicos, respectivamente, nuestro autor subraya la perniciosa tendencia hacia el egoísmo y el peligro de degradación del espíritu público que el individualismo puede traer consigo. De manera que, según el diagnóstico tocquevilleano, estamos ante una tendencia característica de la sociedad democrático-moderna que presenta, de entrada, un carácter ambivalente: puede propiciar el egoísmo y la indiferencia hacia la vida pública o puede alentar la defensa del valor del individuo frente al totalitarismo social y/o político, sea éste tradicionalista o colectivista. Se tratará por tanto - piensa nuestro autor- de analizarlo con sumo cuidado y sin dejarse llevar ni por la adhesión acrítica que muestran algunas corrientes liberales ni por el rechazo simplista que se observa en los autores anti-individualistas. La posición de Tocqueville es, en este sentido, teóricamente complicada porque ¿cómo conciliar la denuncia de los males individualistas con la defensa de la libertad individual? y, a renglón seguido, ¿cómo armonizar el desarrollo del espíritu de individualidad con el compromiso ciudadano por lo público en una sociedad democrática? En el fondo de la cuestión parecen resonar las influencias intelectuales de las que se nutre su pensamiento: ¿se puede ser, al mismo tiempo, un liberal a lo Montesquieu y un demócrata de corte rousseauniano que reclama el sentido cívico de los clásicos para corregir el egoísmo individualista?, ¿se trata de un conflicto, vivido por nuestro autor, "al modo pascaliano" (Díez del Corral, 1989), entre las razones del espíritu y las razones del corazón? La respuesta de Tocqueville a este dilema puede ser reconstruida, a mi juicio, estudiando detenidamente lo que nos dice acerca de la naturaleza del individualismo.

En un célebre capítulo de la 2. ${ }^{\text {a }}$ parte de La Democracia en América que lleva por título "El individualismo en los países democráticos", Tocqueville nos ofrece una definición del individualismo recurriendo para ello a un análisis 
comparativo con el egoísmo. En este sentido, nos dice lo siguiente:

"El egoísmo es un amor apasionado y exagerado hacia uno mismo que lleva al hombre a referir todo a sí solo y a preferirse a todo. El individualismo es un sentimiento reflexivo y pacífico que predispone cada ciudadano a aislarse de la masa de sus semejantes y a retirarse a un lugar alejado con su familia y amigos, de tal manera que tras haberse creado asi una pequeña sociedad a su modo, abandona gustosamente la grande a si misma" (A. de Tocqueville, 1989, t. 2 , 137).

A pesar de guardar un cierto parecido entre sí -ambos suponen repliegue de los individuos sobre sí mismos y desinterés por lo público- se trata, puntualiza Tocqueville, de fenómenos que no deben de ser confundidos ya que ambos difieren en cuanto a su procedencia, naturaleza y consecuencias. En efecto, mientras el origen del egoísmo se pierde, por así decirlo, en la noche de los tiempos y se observa, en mayor o menor medida, en todas las sociedades ("es un vicio tan antiguo como el mundo y no pertenece más a una sociedad que a otra"), el individualismo surge de la sociedad democrática y su incremento está relacionado con el avance de la igualdad ("es de origen democrático y amenaza con desarrollarse a medida que se igualan las condiciones"). El egoísmo -prosigue nuestro autor- es de naturaleza claramente irracional ("nace de un instinto ciego"), mientras que el individualismo pertenece, en el fondo, a la esfera de lo racional ("procede de un juicio erróneo más que de un sentimiento depravado"). El egoísmo, finalmente, impide el crecimiento de cualquier virtud ("reseca el germen de todas las virtudes"), mientras que el individualismo ataca principalmente el desarrollo de las virtudes públicas, pero puede, a la larga, acabar con todas las demás para ir a desembocar en el egoísmo ("no ciega en principio más que la fuente de las virtudes públicas, pero a la larga ataca y destruye todas las otras y va finalmente a absorberse en el egoísmo"). A mi entender, la principal conclusión que se desprende de esta comparación es que el individualismo, a diferencia del egoísmo, no designa un defecto inscrito en la naturaleza humana, sino una nueva moral surgida de la sociedad democrático-moderna que, aislando a los individuos y sumergiéndoles en su vida privada, acaba por degradar su condición misma de ciudadanos. De esta reflexión deriva el que será para Tocqueville, como antes para Rousseau, el principal problema que se le plantea a la filosofía política moderna: a saber, ¿cómo convertir al individuo en ciudadano? (Lamberti, 1983, 221). El obstáculo más importante, según nuestro autor, es el individualismo porque "seca las virtudes públicas" y concentra a los individuos en su vida privada. Urge por tanto -razona el aristócrata normando- analizar en profundidad tanto la estructura ilusoria como las principales consecuencias de este déficit cívico para saber cómo puede ser corregido. Todo ello indica, a mi juicio, que el problema clave de nuestras modernas democracias consiste en moralizar al individuo para convertirlo en un verdadero ciudadano. $Y$ esta tarea supone, fundamentalmente, la corrección de la tendencia que lo inclina hacia el individualismo con los recursos de los que dispone la propia democracia.

La crítica del aristócrata normando al individualismo comprende, a mi modo de ver, dos aspectos fundamentales e intimamente correlacionados: en primer lugar, una denuncia de los peligros despóticos que amenazan a las sociedades democráticas cuando sus miembros, dominados por la tendencia individualista, se repliegan en la esfera privada y se desentienden de las responsabilidades que les corresponden en tanto que ciudadanos; $y$, en segundo lugar, una propuesta de superación, en clave humanista, de la perspectiva que concibe al individualismo como figura antroponómica propia de la democracia liberal.

En cuanto al primer aspecto, Tocqueville muestra, de manera fehaciente, cómo la carencia de civismo que trae consigo el individualismo procede, en el fondo, de un "juicio erróneo" cuya fórmula general encontramos resumida en la siguiente cita: los individuos tienden a "considerarse aisladamente y se complacen en creer que su destino entero está en sus manos" (A. de Tocqueville, 1989, t. 2 2, 138). Así pues, el error en el que incurre el individualista consiste, fundamentalmente, en creerse un individuo autosuficiente. Se trata, en realidad, de una ilusión, ya que su vida como individuo, lejos de estar enteramente en sus manos, depende de su relación con los demás y de su participación como ciudadano en el gobierno de los asuntos comunes. A este respecto, cabe señalar que uno de los principales objetivos de la "nueva ciencia política" que avanza Tocqueville consiste precisamente en desmitificar la ilusión individualista y proponer, en consecuencia, los antídotos adecuados para combatirla. $Y$ es que si no corregimos, piensa nuestro autor, la ilusión de autosuficiencia individual que preside la conducta individualista en todas sus manifestaciones, 
el individuo acabará convirtiéndose en un ser aislado y egoista, en un mero consumidor de bienestar material y no en un verdadero ciudadano. Caldo de cultivo, pues, para la gestación de nuevos despotismos bajo el manto protector de una aparente democracia y con la justificación demagógica de favorecer así la prosperidad general.

Sin la pretensión de ser exhaustivos, podemos decir que la susodicha ilusión individualista adopta al menos cuatro formas principales en la sociedad democrática.

La primera de ellas consiste en creer que los intereses de cada uno -los intereses privados- pueden definirse y maximizarse con independencia de los intereses generales. La cuestión no estriba aquí en que el interés individual, y ya no la virtud entendida al modo clásico, se haya convertido en el principal resorte de la acción humana en la sociedad democrático-moderna, sino en la forma mediante la que se entiende dicho interés individual. El ejemplo de la sociedad norteamericana, sostiene Tocqueville, nos enseña a distinguir entre esta visión errónea, groseramente utilitarista e individualista del propio interés, y una visión ilustrada y "bien entendida" del mismo. Según él, la primera reduce el interés individual a lo meramente económico, lo concibe ingenuamente como si se tratase de algo natural y previamente constituido a la relación social, tiende a confundirlo con el egoísmo y, finalmente, cree ilusoriamente que el interés general no es más que la suma de los intereses particulares. La segunda, por el contrario, define el interés particular como una construcción social e insiste, a partir de ahi, en la necesidad de hacer comprender a los individuos que no son autosuficientes y que su propio interés se halla estrechamente vinculado a la construcción justa del interés general. Puede que esta doctrina del "interés bien entendido" -viene a decirnos Tocqueville- no baste para hacer a los hombres virtuosos, pero limita su inclinación hacia el egoismo; puede que no sea una barrera suficiente para evitar las tentaciones despóticas de mayorias 0 minorias, pero las cuestiona al mostrar que lo público es, justamente considerado, cosa de todos y no de los más 0 de unos cuantos; puede que no impida que los individuos piensen ante todo en sí mismos, pero les hace ver que serán mejores individuos si son también ciudadanos; puede que no libere a los hombres de la pasión por el bienestar material, pero les hace comprender que su satisfacción por parte de todos depende de una distribución equitativa de los bienes producidos; puede, finalmente, que no aparte a los sujetos de la propensión a obrar por interés, pero les enseña que el interés por lo humano es, entre todos, el único realmente valioso e interesante. Por todo ello concluye nuestro autor:

"No temo decir que la doctrina del interés bien entendido me parece la más apropiada, de todas las doctrinas filosóficas, para las necesidades de los hombres de nuestro tiempo y que veo en ella la más poderosa garantía contra ellos mismos que les queda. (...) Instruidlos, pues, en ella a toda costa, porque el siglo de los sacrificios ciegos y de las virtudes instintivas huye ya lejos de nosotros y veo aproximarse el tiempo en que la libertad, la paz pública y el orden social mismo no podrán prescindir de la cultura" (A. de Tocqueville, 1989 t. $\left.^{\circ} 2,162 \mathrm{~s}\right)$.

Partiendo de esta idea, Tocqueville trata de demostrar que el remedio democrático más eficaz y legítimo que tenemos a nuestro alcance para corregir esta forma de ilusión individualista, y conseguir un acuerdo justo entre los intereses particulares y el interés general, pasa, fundamentalmente, por el ejercicio de la libertad política, esto es, por la participación activa de los hombres, en tanto que ciudadanos, en la dirección de los asuntos públicos:

"Para que la democracia impere -subraya nuestro autor en esta dirección-, se precisan ciudadanos que se interesen en los negocios públicos, que tengan la capacidad de comprometerse y que deseen hacerlo. Punto capital al que hay que volver siempre" (citado por Schleifer, 1984, 267).

En estrecha relación con la anterior, la segunda de las ilusiones del individualismo consiste en creer que los individuos pueden ocuparse, sin peligro alguno para su libertad, de sus intereses económicos con independencia de sus responsabilidades ciudadanas. Dicha ilusión imprime al individualismo un sesgo economicista que se manifiesta, dice nuestro autor, en el gusto desmedido que los individuos de la sociedad democrática sienten por el bienestar material.

Tocqueville reconoce, de entrada, el estrecho lazo existente entre la prosperidad económica y la libertad a lo largo de la historia. Ahora bien, a diferencia de los partidarios entusiastas del liberalismo económico, señala el riesgo de despotismo que entraña el descuido de los deberes cívico-políticos por parte de unos individuos estrechamen- 
te concentrados en su bienestar material e ilusoriamente confiados en las bondades del libre mercado. En efecto, cuando se vuelve excesivo, el gusto por el confort económico detrae a los individuos de la vida política, lo cual puede ser aprovechado por un déspota cualquiera -un hombre ambicioso, un partido político, una facción, etc.para minar sutilmente la democracia en nombre del orden público necesario para la prosperidad material. Así pues,

"sucede a menudo en los pueblos democráticos que el gusto por el bienestar material hace abandonar la libertad (...). Si en este crítico momento, un hábil ambicioso llegase a apoderarse del poder, encontraría abierta la vía a todas las usurpaciones. Si durante algún tiempo tiene cuidado de que todos los intereses materiales prosperen, se tenderá a disculpar fácilmente todo lo demás. Sobre todo, que garantice el buen orden (...). Una nación que sólo pide a su gobierno el mantenimiento del orden es ya esclava en el fondo de su corazón: es esclava de su bienestar, y el hombre que debe encadenarla puede aparecer muy pronto. El despotismo de las facciones no es menos de temer que el de un hombre" (A. de Tocqueville, 1989, t. 2 2, 180, 182).

No debemos, pues, confundir sin más el progreso democrático con el progreso económico, ni tampoco creer que el primero se deriva automáticamente del segundo. El error del individualismo consiste aquí en creer que la libertad económica y el bienestar material que ella procura no guardan más que una relación indirecta y no-fundamental con la libertad política, cuando lo cierto es que, sin esta última, la propia libertad económica se encuentra amenazada y la prosperidad material resulta injustamente distribuida.

La tercera ilusión individualista consiste en creer que los individuos pueden realizarse libremente en la esfera privada sin asumir su responsabilidad de ciudadanos 0 , más exactamente, reduciendo a su mínima expresión -el sufragio periódico- el ejercicio de su libertad política. Dicha ilusión se basa, según Tocqueville, en una idea errónea -por reduccionista y limitada- de la libertad, esto es, el concebirla solamente como un derecho dirigido a proteger la independencia privada y no como un deber de participación activa en la dirección de lo público. Y es que la libertad del burgués separada de la libertad del ciudadano, viene a decir nuestro autor, no es más que un espejismo. En efecto, el déficit de participación política, motivado por el retiro de los individuos a su vida privada, supone dejar en manos de los gobernantes la gestión exclusiva de lo público y ello propicia que éstos puedan administrar despóticamente hasta la privacidad misma de aquéllos. En este sentido, el sufragio periódico no es suficiente para frenar esta peligrosa tendencia, ya que, según nuestro autor,

"resulta difícil concebir cómo unos hombres que han renunciado enteramente al hábito de dirigirse a sí mismos podrían elegir bien a los que deben dirigirlos, y no cabe creer que de los sufragios de un pueblo de criados pueda alguna vez salir un gobierno liberal, enérgico y sabio" (A. de Tocqueville, 1989 t. $\left.^{\circ} 2,376\right)$.

El repliegue de los individuos sobre sí mismos, la falta de solidaridad social, la despolitización y la carencia de un espíritu público democrático son los principales efectos negativos asociados a la mencionada ilusión. De persistir ésta, advierte, el ciudadano puede convertirse en un siervo democrático y con ello la aparición del despotismo está verdaderamente servida. El inconveniente de esa libertadindependencia radica, pues, en el fomento de un aislamiento individual que lejos de suponer, como aparenta, un incremento de la libertad de los sujetos, los sumerge en realidad en el egoísmo y los sitúa totalmente a merced de una administración estatal cada vez más paternalista, burocratizada y todopoderosa. Para corregir esta ilusión de la autosuficiencia privada generada por el individualismo y el peligro de despotismo que trae consigo, Tocqueville insiste en el papel fundamental que desempeñan las asociaciones ciudadanas, ya que ellas constituyen, según señala, esos cuerpos intermedios capaces de frenar la dependencia del individuo respecto al Estado y de generar el encuentro entre las dimensiones civil y política de la libertad en una sociedad democrática. En este sentido, "la ciencia de la asociación" es considerada por él como "la ciencia madre de los países democráticos" (A. de Tocqueville, 1989, t. ${ }^{2}$, 150) e interpretada como un medio fundamental para la educación democrática de la ciudadanía.

La cuarta y última forma de ilusión individualista hace referencia a esa especie paradójica de autosuficiencia que muestra comúnmente el hombre democrático en materia intelectual. Dicha autosuficiencia le lleva, por un lado, a cuestionar las fuentes de la autoridad tradicional en nombre del juicio individual, pero, al mismo tiempo, tiende a creer que la verdad se encuentra en la opinión de la mayo-

ARBOR Vol. 187750 julio-agosto [2011] 691-704 ISSN: 0210-1963

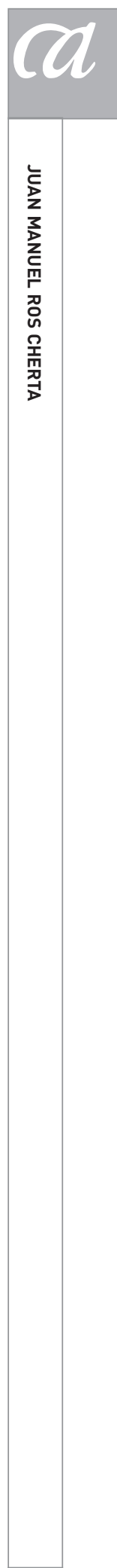

695 
ría. La explicación de semejante paradoja hay que buscarla, según nuestro autor, en el individualismo intelectual que genera el igualitarismo democrático. En efecto, el individualismo impulsa a cada individuo a buscar la verdad en sí mismo y, simultáneamente, hace que cada cual vea en el otro, semejante a él, una verdad equivalente a la suya. Ahora bien, por grande que sea la independencia individual en el dominio del pensamiento, ésta tiene sus límites $y$, por tanto, hace falta -dice Tocqueville-, que la autoridad intelectual se encuentre en alguna parte. Sí, pero ¿dónde? La misma semejanza de los individuos les inclina a pensar que se halla en el juicio del mayor número, en la mayoría, y con ello creen haber resuelto la cuestión. Se trata, afirma nuestro autor, de una solución reconfortante, pero ilusoria, ya que trueca la independencia intelectual del individuo en dependencia de la opinión común, y de ahí a la "tiranía de la mayoría" no hay más que un paso muy pequeño. Así pues, el individualista cree, ilusoriamente, seguir su propio punto de vista cuando, en realidad no hace sino conformar sus ideas a la opinión mayoritaria. En este sentido, dice R. Bellah acertadamente que

"la confianza del individualista en sus propias opiniones y la conformidad ansiosa con las ideas de sus semejantes resultan ser las dos caras de una misma moneda" (Bellah, 1989, 196).

El lazo que une al individualismo intelectual con "la tiranía de la mayoria" constituye, pues, una de las fuentes del despotismo democrático más peligrosas por lo sutil y difícil de combatir que resulta. Y ello porque el imperio de la mayoría se confunde en la opinión común con la definición misma de la democracia. Convertida así en dogma que se asume de modo inconsciente y se acepta sin discutir, la opinión mayoritaria está llamada a ser la nueva religión de los tiempos democráticos, y su omnipotencia la marca de fábrica del nuevo despotismo que les amenaza. En efecto,

"La fe en la opinión común es la fe de las naciones democráticas. La mayoría es el profeta. En las naciones democráticas, el imperio moral de la mayoría está llamado quizá a reemplazar hasta cierto punto a las religiones, o a perpetuar a algunas si las protege. Pero entonces la religión se vivirá como opinión común más que como religión (...). Hay en ello, y nunca podria repetirlo demasiado, motivo para hacer reflexionar a los que ven en la libertad de la inteligencia una cosa santa y odian no solamente al déspota, sino también al despotismo" (A. de Tocqueville, 1989, t.o 2, 31, 34).

Más que cualquier opresión legal, política o administrativa, lo que le preocupaba verdaderamente al aristócrata normando era la tiranía sutil y profunda sobre las ideas, sentimientos y valores del individuo que una mayoría podía establecer y justificar amparándose en el igualitarismo democrático. Por este motivo busca, valiéndose del ejemplo americano, los remedios que puedan frenar esta tendencia y la manera de corregir la ilusión individualista en la que se funda. El error de la autosuficiencia intelectual, propio del individualismo democrático, puede ser corregido -arguye nuestro autor-, mediante la participación de los sujetos en los asuntos públicos -ya sea en las instituciones, ya sea en las asociaciones voluntarias-, ya que dicha acción les enseña a no confundir la autonomía intelectual con la autosuficiencia individualista $y$, al mismo tiempo, les hace salir de sí mismos para actuar en común como ciudadanos.

\section{El humanismo cívico de A. de Tocoueville}

De todo el análisis precedente podemos inferir que la crítica tocquevilleana al individualismo no se limita a señalar a éste como a uno de los factores que propician la aparición del despotismo democrático, sino que también propone, a mi juicio, algo de mayor trascendencia: a saber, un humanismo cívico que trata de superar la concepción individualista del hombre que ofrece el liberalismo clásico como fundamento antropológico de la democracia moderna.

Es cierto que nuestro autor no nos ofrece en La Democracia en América -ni en ninguna otra parte de su obra- un tratamiento completo y sistemáticamente elaborado de sus ideas antropológicas. Ello no significa, sin embargo, que tales ideas no aparezcan reflejadas, una y otra vez, al hilo de su reflexión sobre la democracia norteamericana, y muy especialmente en la segunda de sus partes. A este respecto, cabe subrayar que Tocqueville no solamente retrata, con una penetración filosófica extraordinaria, al homo democraticus tal y como es, sino que además nos dice cómo debería ser para evitar su degradación en el egoísmo individualista. En el fondo de su teoria se encuentra, pues, una antroponomía democrática que trata de preservar la 
dignidad del hombre e impedir su degeneración espiritual. A mi modo de ver, dicha antroponomía tiene un carácter humanista y no individualista, porque lo que defiende Tocqueville es la autonomía y no la autosuficiencia de los individuos; es la participación en lo público y no la independencia privada; es el asociacionismo y no la atomización social; es el compromiso cívico y no el consumo de bienestar material; es la responsabilidad moral y no la maximización egoísta del beneficio; son los "hábitos del corazón" y no la protección legalista de los derechos; y, en definitiva, es el ciudadano y no el derechohabiente. No se trata, sin embargo, de sacrificar al individuo para recuperar al ciudadano, como pensaba Rousseau, pero tampoco de que la ciudadanía sea nada más que un instrumento defensivo al servicio de la privacidad individual, como sostenía Constant. El humanismo cívico de Tocqueville trata, a mi juicio, de superar ambos extremos -el republicano y el liberal-, y, en este sentido, lo que pretende es restituir al ciudadano sin anular por ello al individuo. Pero, ¿cuáles son los principales rasgos de este humanismo cívico que, según nuestra interpretación, propone Tocqueville como ethos democrático? A mi modo de ver, serían los siguientes:

\section{Autonomía individual}

Para nuestro autor, no hay civismo verdaderamente democrático sin la consideración nuclear del hombre -de todo hombre-, como sujeto capaz de pensar, de sentir y de actuar por sí mismo; en una palabra, capaz de autogobernarse. En este sentido, el ejercicio de la libertad -un ejercicio ilustrado y responsable, sí, pero sobre todo apasionado- constituye, según señala, lo propio del ser humano y lo que le confiere valor moral, dignidad por encima de cualquier otra prerrogativa, ya sea de tipo holista ["todas las doctrinas que permiten al cuerpo social pisotear a los hombres y que hacen todo de la nación y nada de los ciudadanos" (A. de Tocqueville, 1954, VI, 1, 53)] ya sea de tipo individualista ["ese vicio propio del corazón humano que no ciega en principio más que la fuente de las virtudes públicas, pero que a la larga ataca y destruye todas las otras y va finalmente a absorber al hombre en el egoísmo" (A. de Tocqueville, 1989, t. ${ }^{2}$, 136)].

La libertad es, ciertamente, la gran pasión de Tocqueville, el auténtico leitmotiv de toda su reflexión, y de ahí su esfuerzo por mostrar que ella es el fundamento de la grandeza moral del hombre y la raíz de una individualidad plenamente autónoma. A este respecto, se ha señalado (Schleifer, 1984, 256, 281) -a mi juicio acertadamente-, que el individuo autónomo y moralmente responsable es, en el fondo, la figura protagonista de La Democracia en América y que la defensa de la dignidad de cada ser humano constituye, en todo caso, "el meollo de la obra"4. Tocqueville no aboga, pues, por una libertad-privilegio reservada a una minoría aristocrática. Nadie como él advirtió que, tras la Revolución Francesa, la libertad ya no podía ser legítimamente fundada sobre la desigualdad y la jerarquía. En la sociedad democrática, una noción justa acerca de la libertad ha de ser la de un derecho igual para todos a la autonomía individual. Ahora bien, nadie mejor que él avistó el peligro que corría la autonomía del individuo ante el desarrollo de una sociedad democrática proclive a convertir la igualdad en igualitarismo, la individualidad en individualismo, el universalismo moral en homogeneización axiológica y la búsqueda de la felicidad en hedonismo materialista. De predominar esta tendencia -viene a decirnos Tocqueville-, la autonomía individual se verá limitada, en el mejor de los casos, al derecho a una vida privada independiente que resulta, a la postre, ilusoria sin la consideración de las obligaciones cívico-políticas que la propia autonomía comporta, esto es, la participación activa y responsable de los individuos en la dirección de los asuntos públicos. En este sentido, la libertad-participación no es solamente una estrategia defensiva de la libertadindependencia, sino que constituye, podríamos decir, su fundamento racional práctico.

Nada más opuesto, por otra parte, al humanismo tocquevilleano que una visión beatífica, exenta de tensiones e ingenuamente optimista de la autonomía. A nuestro autor no se le oculta la enorme complejidad del ser humano, esa criatura que media -como le enseñara su maestro Pascal-, entre "el ángel y la bestia", entre "San Jerónimo y Heliogábalo" (Mayer, 1965, 127 ss) ; y que es, ineluctablemente, un compendio sin solución definitiva de fuerzas buenas y malas. La grandeza moral del hombre consiste, pues, no en negar la bestia, sino en querer que el ángel predomine ${ }^{6}$. Así pues, dadas las tendencias -internas y externas-, que tratan de contrariarla, la autonomía del individuo es un valor que debe ser conquistado día a día; y para ello se requiere, como decía Kant, voluntad racional, sí, pero también y sobre todo, dirá Tocqueville, pasión por la libertad. En este sentido, la autonomía no encuentra su justificación más profunda en una razón formalmente pura como en Kant, 
sino más bien en las razones del corazón de las que hablara Pascal y que nuestro autor interpreta, quizás por influencia de Rousseau, en clave romántico-vitalista. Y ello porque, según nos dice, la libertad se ama por sí misma y no tanto por deber o por los beneficios que procura. A este respecto, escribe lo siguiente:

\begin{abstract}
"Me he preguntado a menudo dónde está el origen de esa pasión por la libertad que en todos los tiempos ha inducido a los hombres a realizar las cosas más grandes llevadas a cabo por la humanidad, en qué sentimientos se enraiza y se nutre. (...) Lo que le ha ganado en todas las épocas el corazón de los hombres son sus mismos atractivos, su propio encanto, con independencia de sus beneficios (...). El que busca en la libertad otra cosa que no sea ella misma está hecho para servir" (A. de Tocqueville, 1982, I, 177s).
\end{abstract}

Así pues, para Tocqueville la libertad tiene su razón de ser en la propia vivencia de la misma y en la comprensión apasionada de su intrínseco valor humano. Y si bien es cierto que en la libertad se manifiesta la dignidad del hombre, no lo es menos -podríamos concluir siguiendo a nuestro autor-, que es la experiencia radicalmente vivida de la libertad la que hace a los hombres verdaderamente libres.

\section{Espíritu de asociación}

Como hemos apuntado, el humanismo tocquevilleano ve en la libertad entendida como autonomía, y no en la independencia individualista, el fundamento práctico-normativo de una personalidad genuinamente democrática ${ }^{7}$. Ahora bien, para que haya verdadera autonomía, y con más razón todavía para que prospere, hace falta -arguye nuestro autor- que los individuos salgan del estrecho círculo de su vida privada, que deliberen entre ellos qua ciudadanos acerca de los asuntos públicos y que se vinculen solidariamente en torno a valores compartidos e intereses comunes. En este sentido, puede decirse que no hay un yo propiamente autónomo sin la mediación intersubjetiva de un nosotros social que, lejos de anularlo, lo propicie y perfeccione. Quizás la cita que mejor condensa este pensamiento de Tocqueville sea la siguiente:

"los sentimientos y las ideas no cambian, el corazón no se engrandece y el espíritu humano no se desarrolla más que por la acción reciproca de unos hombres sobre otros" (A. de Tocqueville, 1989, t.o 2 , 149).
El individualista liberal yerra, pues, al desconsiderar el decisivo papel que desempeña la interacción social en la constitución y desarrollo de una individualidad plenamente autónoma. La sociabilidad se revela, en este sentido, indispensable para concebir un humanismo que sea capaz, al mismo tiempo, de potenciar la autonomía individual y de superar el egoísmo individualista. La pretensión de conjugar autonomía individual y solidaridad social le llevará frecuentemente a caminar a contracorriente de las teorías liberales de la época ${ }^{8}$.

\section{Es cierto que el autor de La Democracia en América piensa} sobre este punto como un liberal preocupado por idear mecanismos -en este caso, las asociaciones- capaces de contrarrestar y poner límites al crecimiento desmesurado del Estado, pero no es menos cierto que también razona como un demócrata al considerar el asociacionismo ciudadano como un factor decisivo en la vertebración de una sociedad civil "autoorganizada, pluralista e independiente del Estado", sin la que no puede haber una verdadera democracia9 . En este sentido, la teoría de la asociación tendría, a mi modo de ver, el mérito de vincular estrechamente liberalismo y democracia salvando, a la vez, los prejuicios antidemocráticos presentes en la tradición liberal y el peligro despótico que conlleva la realización, desde el Estado, del ideal democrático de los Antiguos. Desde esta óptica, podriamos concluir que el asociacionismo representa para nuestro autor un paso adelante en la configuración ilustrada de una cultura cívico-democrática $y_{1}$ en consecuencia, una vía para hacer de la democracia liberal algo mucho más profundo y radical que un mero sistema de gobierno representativo ${ }^{10}$. Por esta razón -habría que añadir-, resulta particularmente decisiva la educación moral y política de la ciudadanía en los valores que sustentan y contribuyen a perfeccionar críticamente a la propia democracia. En este sentido, puede verse en La Democracia en América, ya desde su misma introducción, una clara vinculación entre sus objetivos político y pedagógico:

"Instruir la democracia, reanimar, si es posible, sus creencias, purificar sus costumbres, regular sus movimientos, sustituir poco a poco su inexperiencia por la ciencia de los asuntos públicos y sus instintos ciegos por el conocimiento de sus verdaderos intereses (...). Hace falta una ciencia política nueva para un mundo enteramente nuevo" (A. de Tocqueville, 1989, t.o 1, 10s). 
No es de extrañar, por tanto, que la obra esté repleta de referencias educativas: el municipio, el jurado $y$, sobre todo, las asociaciones políticas y civiles son vistos de este modo como grandes escuelas abiertas a todos que educan al ciudadano en el espíritu público democrático. Quizás puede resumirse su idea diciendo aquello -tantas veces proclamado como escasamente tomado en serio- de que no puede haber verdadera democracia sin una educación para la democracia.

\section{Sentido de la justicia}

Como hemos visto, Tocqueville considera el asociacionismo ciudadano como una condición indispensable para el desarrollo de la autonomía individual y para la creación de un espíritu público democrático en la sociedad moderna. Ahora bien, a nuestro autor no se le oculta que el individualismo puede reproducirse de nuevo, e incluso verse acrecentado, en el comportamiento de las asociaciones. Esto ocurre, básicamente, cuando las asociaciones obvian toda referencia al interés común y se dedican exclusivamente a perseguir intereses particularistas, o corporativistas, como diríamos hoy. En este caso -advierte-, ciertas asociaciones pueden convertirse en fuerzas oligárquicas y amenazar el proceso democrático con un nuevo género de despotismo: a saber, el ejercido por estas minorias sobre la mayoría. Lo que el aristócrata normando teme, en este sentido, es que los peores vicios de los cuerpos aristocráticos del pasado se repitan bajo una nueva apariencia en la conducta de las asociaciones, ya sea en las de corte específicamente político -léase partidos políticos-, ya sea en las asociaciones de carácter civil.

Por lo que se refiere a las primeras señala, con toda claridad, el peligro de que los partidos políticos se conviertan, en lugar de ser representantes, en mandatarios de la voluntad popular. A este respecto, puede servir como botón de muestra la siguiente observación:

"El despotismo de las facciones no es menos de temer que el de un solo hombre. Cuando la masa de ciudadanos únicamente quiere ocuparse de sus asuntos privados, los partidos (...) no deben desesperar de convertirse en dueños de los asuntos públicos. No es raro ver entonces en el vasto escenario del mundo, así como en nuestros teatros, a una multitud representada por ellos (...). Disponen según sus caprichos de todas las cosas, cambian las leyes y tiranizan a su voluntad las costumbres, y se sorprende uno al ver el pequeño número de débiles e indignas manos en las que puede caer un gran pueblo" (A. de Tocqueville, 1989, t. 2 , 182).

El déficit democrático en el funcionamiento interno de tales asociaciones es, asimismo, blanco de las críticas de nuestro autor. Así, por ejemplo, escribe:

"(...) esas asociaciones se inclinan a darse una organización que no tiene nada de civil y a introducir en su interior hábitos y máximas militares. Así, se las ve centralizar todo lo que pueden la dirección de sus fuerzas y entregar el poder de todos en manos de un número muy pequeño. Los miembros de esas asociaciones responden a un santo y seña, como los soldados en campaña, y profesan el dogma de la obediencia pasiva 0 , más bien, al unirse hacen de una vez el sacrificio de su juicio y su libre arbitrio. De este modo, reina con frecuencia en el interior de esas asociaciones una tiranía más insoportable que la que pueden ejercer en la sociedad en nombre del gobierno" (A. de Tocqueville, 1989, t.o 1, 189).

En lo que se refiere a las asociaciones civiles, valga como ejemplo significativo la preocupación de nuestro autor por la emergencia de una "nueva aristocracia de señores" en el campo de la industria", lo que puede constituir un caso de acción opresiva de una minoría sobre la mayoría que habría que añadir a la consabida prevención de Tocqueville con respecto a la tiranía de las mayorías. Así pues, las asociaciones pueden reproducir en su forma de comportarse los mismos males que con ellas se pretende superar. El ejemplo de la sociedad norteamericana nos muestra -dice Tocqueville- que la solución a este problema pasa por la doctrina del "interés bien entendido", esto es, por hacer comprender a individuos y asociaciones que no es inteligente ni justo en democracia perseguir egoístamente el propio interés particular con independencia del interés general ${ }^{12}$. De lo que se trata, en el fondo, es de responder a la necesidad de armonizar justamente el interés privado y el interés público en una sociedad democrática (Manent, 1991, 70). Queda, sin embargo, la cuestión de aclarar mejor, aunque sea someramente, lo que entiende nuestro autor por "interés bien entendido".

Contra lo que pueda parecer, no estamos ante un mero principio empírico-utilitario elevado a la categoría de teoría social por parte de los norteamericanos y mal comprendido en la Francia de su tiempo. Más profundamente consi-

ARBOR Vol. 187750 julio-agosto [2011] 691-704 ISSN: 0210-1963

(1)


derado, el "interés bien entendido" puede ser interpretado, a mi juicio, como un criterio democrático de justicia que pone en tela de juicio las visiones de ese mismo criterio que contaban con mayor predicamento en el ambiente intelectual de la época (y que son todavía, en buena medida, los de la nuestra): a saber, la regla de mayorías, la mano invisible del mercado y la voluntad general roussouniana.

A mi modo de ver, Tocqueville se inspira aquí en el pensamiento de su venerado maestro intelectual P. P. RoyerCollard ${ }^{13}$, aunque sea, como veremos inmediatamente, para ir más allá de él. Dos son, principalmente, las ideas que nuestro autor toma del ilustre doctrinario. En primer lugar, la idea, tan apreciada por Royer-Collard, "d'appliquer la morale aux grandes choses"14, de donde deriva Tocqueville el carácter ético-normativo del principio del interés bien entendido $y_{1}$ en este sentido, su papel de instancia legitimadora de la praxis democrática. En segundo lugar, la definición doctrinaria de la justicia como "soberanía de la razón"15, lo que significa para Tocqueville una visión de indole formal y universalista de la misma cuyo referente ideal son los Derechos del Hombre. Desde esta perspectiva, el principio del interés bien entendido no puede ser identificado sin más -arguye nuestro autor- con la regla de mayorías porque

"la mayoría, en sí, no es todopoderosa; por encima de ella, en el reino moral, están la humanidad, la justicia y la razón (...). La mayoría, en su omnipotencia, debe reconocer estas dos barreras y si alguna vez las ha echado abajo, es porque, como los hombres que la componen, se ha rendido a las pasiones y se ha visto arrastrada por ellas más allá de sus derechos" (A. de Tocqueville, 1989, t. 1 1, 374).

En otro pasaje de La Democracia en América l insiste nuestro autor en esta misma idea al sostener que la más alta limitación del gobierno de la mayoría es sobre todo de carácter moral y no jurídico, es la justicia y no tanto la legalidad. En este sentido, escribe:

"La justicia forma, pues, el límite del derecho (a mandar) de cada pueblo. Una nación es como un jurado encargado de representar la sociedad universal y de aplicar la justicia que es su ley. El jurado, que representa a la sociedad, ¿debe tener más poder que la sociedad misma cuyas leyes aplica? Así pues, cuando me niego a obedecer una ley injusta, no niego a la mayoria el derecho a mandar, apelo solamente a la soberanía del género humano contra la soberanía del pueblo" (A. de Tocqueville, 1989, t. ${ }^{1}$ 1, 246).

Tampoco puede ser el interés bien entendido confiado a la mano invisible del mercado porque ello supondría -viene a decir nuestro autor- minusvalorar el papel de la libertadparticipación de los ciudadanos y su responsabilidad en la construcción de un interés común. A este respecto, indica Lamberti que la primera condición de un verdadero acuerdo entre los intereses particulares y el interés general es, para Tocqueville, "la libertad política y no la libertad económica" (Lamberti, 1983, 233). Finalmente, la voluntad general roussouniana presenta el inconveniente de confundir lo que es un principio de legitimación moral con la aplicación político-social de dicho principio, lo cual trae consigo que la voluntad general sea suplantada demagógicamente por la voluntad particular de una mayoría, de una minoría o de un solo individuo, con el consiguiente riesgo de despotismo. Como es sabido, ésta es, en esencia, la crítica liberal de Constant a Rousseau. Nuestro autor sigue aqui esta dirección y, aunque no cite a Constant ni se refiera explícitamente a Rousseau, repite mutatis mutandi esta misma objeción en contra del carácter ilimitado de la soberanía popular cuando afirma:

"La omnipotencia me parece en sí misma una cosa mala y peligrosa (...). No hay sobre la tierra autoridad tan respetable en sí misma o revestida de un derecho tan separado que yo quiera dejarla actuar sin control y dominar sin obstáculos. Asi, pues, cuando veo conceder el derecho y la facultad de hacerlo todo a un poder cualquiera, llámese pueblo o rey, democracia o aristocracia, ejérzase en una monarquía o en una república, digo: ahí está el germen de la tiranía, y trato de ir a vivir bajo otras leyes" (A. de Tocqueville, 1989, t. $\left.{ }^{1}, 246\right)$.

Así pues, lo que Tocqueville llama "interés bien entendido" es, en definitiva, un criterio normativo de justicia que sirve tanto para orientar la praxis de individuos y asociaciones, en el sentido del interés universalizable, como para cuestionar sus eventuales desviaciones despóticas y antidemocráticas.

\section{Voluntad de excelencia}

La comparación entre los tipos ideales de aristocracia y democracia constituye, como es sabido, uno de los resortes 
fundamentales del pensamiento político de Tocqueville. Además de las vertientes sociológica e histórica, dicha comparación contiene, a mi juicio, una dimensión éticoantropológica de la mayor importancia para entender el sentido de la crítica tocquevilleana al individualismo democrático y su reivindicación de un homo democraticus con voluntad de excelencia 0 , si se prefiere decirlo así, que no se contente con esa especie de personalidad mediocre, conformista y uniforme que tiende a engendrar la democracia de masas. A este respecto, podríamos decir que su argumentación comprende dos aspectos claramente interrelacionados. En primer lugar, un agudo cuestionamiento de los valores individualistas que genera la cultura democrática como son, principalmente, la pasión igualitarista, el culto obsesivo al bienestar material, la búsqueda de la realización en la esfera privada y la conformidad con la mayoría. En segundo lugar, una referencia normativa a ciertos valores ligados a la concepción aristocrático-liberal de la libertad, cuyas raíces espirituales provienen tanto del republicanismo clásico como de la tradición nobiliaria medieval con la que nuestro autor se halla emparentado. Se trata, básicamente, del espíritu de individualidad, el sentimiento de grandeza espiritual y la dedicación apasionada a los asuntos públicos.

Si bien es cierto que su apreciación de tales valores aristocráticos resulta, en ocasiones, "ingenuamente romántica y peca de excesiva idealización" (Furet, 1980, 195s) esto no debe hacernos perder de vista su principal intención al recurrir a ellos: abrir el espíritu y el corazón del hombre democrático a proyectos de vida más elevados y a otras formas de ejercer la libertad que conecten de nuevo la realización personal con la participación en la cosa pública. Tocqueville no preconiza ningún retorno al universo aristocrático -cosa en extremo difícil e injustificable para un moderno como él-, sino que pretende introducir el espiritu de la libertad aristocrática en el seno mismo de la cultura democrática con el muy noble objetivo de combatir sus perniciosas tendencias hacia la masificación social, la indiferencia política, el consumismo materialista o la mediocridad espiritual. Lo que teme, fundamentalmente, nuestro autor es que al inmovilismo del pasado, basado en la tradición y el privilegio de unos cuantos, le suceda ahora un nuevo inmovilismo democrático que descanse en una opinión pública mayoritaria tendente a confundir el individualismo con la individualidad, el igualitarismo con la igualdad, la homogeneización espiritual con la extensión de la ilustración o la maximización utilitaria con la excelencia humana. En este sentido, escribe Lamberti:

"Toda su obra es un inmenso esfuerzo para trasponer a la democracia, y en beneficio suyo, los valores aristocráticos $y$, en primer lugar, el gusto por la excelencia humana, el respeto mutuo y la orgullosa afirmación de la independencia personal, los cuales constituyen, tanto para él como para Chateubriand, la esencia de la libertad aristocrática" (Lamberti, 1983, 77).

Tocqueville es consciente de que la proyección del espiritu aristocrático-liberal en la sociedad democrática no puede traspasar ciertos límites sin atentar contra la sustancia misma de la democracia, pero también sabe que forma parte esencial de la propia idea democrática la necesidad constante de perfeccionarse a sí misma como única salida para evitar su anquilosamiento espiritual $y_{\text {, lo que es aún }}$ peor, su degeneración despótica. Ello le lleva a confesarle a J. Stuart Mill que

"la peor enfermedad que amenaza a los pueblos democráticos es el debilitamiento gradual de las costumbres, el rebajamiento de los espíritus, la mediocridad de los gustos; es de este lado donde se encuentran los grandes peligros de su porvenir" (A. de Tocqueville, 1954, t. $\mathrm{VI}, \mathrm{I}, 335$ ).

Para nuestro autor, se trata, por tanto, de introducir en el terreno del saber, en las costumbres y en la vida socio-política democrática la aspiración a la excelencia con el fin de aumentar la calidad propiamente humana de los individuos y contener, en la medida de lo posible, el debilitamiento moral generalizado que tiende a inducir el igualitarismo democrático. Así pues, conviene fomentar, en el campo de las ciencias, el puro deseo de conocer y el amor a la verdad; y en el de las artes, la aspiración a la belleza y el ansia de perfección en las obras, con el propósito de contrarrestar el sesgo práctico-utilitario y el consiguiente empobrecimiento espiritual que imprime en dichas materias el estado social democrático ${ }^{16}$. Algo análogo cabe hacer en el ámbito de las costumbres, pues se trata de evitar que esa especie de ambición desproporcionada, mediocre y presentista por el bienestar material, tan propia de los tiempos democráticos que corren, acabe por borrar enteramente del espíritu del hombre los sentimientos nobles y las pasiones elevadas. En el terreno político, finalmente, hay que conseguir que las asociaciones ciudadanas se erijan en "personas 
aristocráticas" ilustradas e influyentes a las que no se las pueda pisotear fácilmente y que, sin reproducir los errores e injusticias de la antigua aristocracia, sirvan para frenar la omnipotencia de la mayoría y las tendencias opresivas derivadas del incremento del poder estatal y/o mercantil.

En definitiva, la cultura democrática no tiene por qué estar necesariamente reñida con la aspiración a la excelencia humana y ésta, a su vez, no tiene por qué ser concebida como algo reservado a unos pocos y sí como un haz de posibilidades abierto a la mejora espiritual de cada uno y al mutuo perfeccionamiento de todos. En este sentido, podríamos concluir con nuestro autor que

"es necesario que todos los que se interesen por el futuro de las sociedades democráticas se unan y que todos, de común acuerdo, realicen continuos esfuerzos para propagar en esas sociedades la afición al infinito, el sentimiento de lo grande y el amor a los goces inmateriales" (A. de Tocqueville, 1989, t. 2 , 186).

\section{NOTAS}

1 Es el caso, por ejemplo, de J. Stuart Mill que saludó la obra como el primer gran tratado filosófico sobre la democracia moderna.

2 Este artículo se propone precisamente ahondar en esa dimensión filosófica del pensamiento político de Tocqueville aunque para ello, claro está, haya de tener en cuenta sus aspectos metodológicos. Para un análisis detallado sobre dicha dimensión, véase Ros, 2001.

3 Ésta es la línea interpretativa que, desde que R. Aron la iniciara (Aron, 1970), domina la mayor parte de los trabajos sobre Tocqueville hasta el punto de haberse convertido ya en un lugar común.

4 Más profundamente todavía podríamos considerar que lo que formula Tocqueville es un "humanismo eleuteronómico" (Conill, 1991), ya que su defensa de la libertad como raíz de la humanidad misma del hombre hace que su posición vaya mucho más allá de un simple humanitarismo y/o de un civismo meramente exterior y superficial.

Recibido: 7 de septiembre de 2010 Aceptado: 10 de enero de 2011
5 J. P. Mayer insiste en la importancia que tiene la reflexión antropológica éticamente orientada en la filoso- fía política de Tocqueville y añade, además, el siguiente comentario crítico sobre la filosofía política que se practica hoy en día: "El enigma de la naturaleza humana es el punto de partida de toda filosofía política; y esto es precisamente lo que nuestro moderno pensamiento político, miope y superficial, tan a menudo ciego para cuanto trascienda de los fines inmediatos, parece haber olvidado". A este respecto, no estaría de más recordar, siguiendo a la profesora $\mathrm{A}$. Cortina, que la "marca de fábrica" de la filosofia politica, desde sus orígenes griegos, no es otra que la "de hacer a los hombres mejores" (Cortina, 1995, 433).

$6 \mathrm{M}$. Bressolette habla, en este sentido, de un "humanismo de la tensión" en Tocqueville (Bressolette, 1974, 10). En una dirección similar, véase también Díez del Corral, 1989, 250s.; Lawler, 1992, 1-20.

7 Sobre el valor de la autonomía en Tocqueville, y en contra de las lecturas "neotocquevillianas" que pretenden asimilarla a la independencia individualista, véase Renaut, 1998, 108-130.

8 La preocupación tocquevilleana por encontrar un principio moderno de integración social que combine li- 
bertad individual e interés común, le aleja -señala A. Touraine- tanto del liberalismo económico del laissezfaire como del liberalismo político de Constant (Touraine, 1994, 185s). En un sentido parecido se pronuncia R. Boesche, quien ve en la obra de Tocqueville un intento de síntesis entre el liberalismo constantiano y el democratismo radical roussouniano (Boesche, 1987, 265s).

9 Sobre esta conexión entre asociacionismo, sociedad civil y democracia liberal en Tocqueville (Keane, 1992, 75s).

10 No es de extrañar, en este sentido, que algunos teóricos actuales de la democracia -D. Held, por ejemplo-, sitúen a Tocqueville junto a J. Stuart Mill entre los principales representantes del modelo "desarrollista-liberal" de la democracia decimonónica y que lo consideren, además, como una fuente importante de inspiración para la teoría contemporánea de la democracia (Held, 1992, 116).

11 A analizar este peligro dedica Tocqueville el capítulo XX de La Democracia en América // cuyo título reza significativamente "Cómo la aristocracia podría surgir de la industria" (A. de Tocqueville, 1989, t. 2, 201-207).

12 Ésta es la tesis que nuestro autor defiende en el capítulo de La Democracia en América I/ titulado "Cómo los americanos combaten el individualismo con la doctrina del interés bien entendido". No deja de ser interesante para nuestra interpretación el señalar que Tocqueville pensó darle a dicho capítulo el significativo título de "El interés bien entendido como doctrina filosófica". Véase al respecto la nota del editor E. Nolla (Nolla, 1989, 160).
13 La influencia ejercida, en general, por Royer-Collard sobre Tocqueville, y especialmente el intercambio de correspondencia -y de ideas- entre ambos durante la elaboración de la

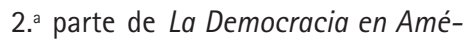
rica, ha sido objeto de varios estudios (Díez del Corral, 1989, 353-393; Lamberti, 1983, 158-173). Ya Ortega y Gasset, con la perspicacia que le era propia, indicó en su día que en la correspondencia entre ambos autores se hallan quizás algunas de las páginas más profundas del pensamiento político de Tocqueville (Ortega y Gasset, 1971, t. 9, 327).

14 Tocqueville sigue a Royer-Collard en la perspectiva de "legitimar la política recurriendo a la moral", lo que supone, en buena lógica, la voluntad de "moralizar la política". La diferencia entre ambos estriba, sin embargo, en que Royer-Collard no supo concebir la posibilidad de una democracia liberal y Tocqueville sí.

15 Sobre este punto Lamberti indica que Royer-Collar y Tocqueville parecen seguir a Montesquieu, quien había afirmado en El espíritu de las leyes que "La ley, en general, es la razón humana, en tanto que ella es la que gobierna todos los pueblos de la tierra; y las leyes políticas y civiles de cada nación no deben ser otra cosa que los casos particulares donde se aplica esta razón humana".

16 Ésta es, en sintesis, la tesis que defiende nuestro autor en los caps. $X$ y

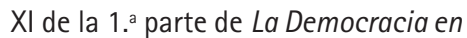
América II titulados, respectivamente, "Por qué los americanos se aplican más a la práctica de las ciencias que a la teoria" (pp. 68-77) y "Con qué espiritu cultivan las artes los americanos" (pp. 77-82) (A. de Tocqueville, 1989 , t. 1).

\section{BIBLIOGRAFÍA}

Aron, Raymond (1970): Las etapas del pensamiento sociológico, Buenos Aires, Siglo XX.

Bellah, Robert y otros (1989): Hábitos del corazón, Madrid, Alianza.

Boesche, Roger (1987): The strange liberalism of Alexis de Tocqueville, New York, Cornell University Press.

Bressolette, Michel (1974): L'humanisme d'Alexis de Tocqueville, Toulouse, Bulletin de la Société d'Études Classiques, n. 169.

Conill, Jesús (1991): El enigma del animal fantástico, Madrid, Tecnos.

Cortina, Adela (1995): "¿Qué puede aportar la filosofía política a la presunta politica europea?", en W.AA., La filosofía ante la encrucijada de la nueva Europa, Madrid, Diálogo Filosófico.

Díez del Corral, Luis (1989): El pensamiento político de Tocqueville, Madrid, Alianza.

Furet, François (1980): Pensar la Revolución Francesa, Badalona, Petrel.

Held, David (1992): Modelos de democracia, Madrid, Alianza.

Hhennis, Wilhelm (1991): "In search of the 'new science of politics'", en K. Masugi (ed.), Interpreting Tocqueville's Democracy in America, Maryland, rowman\&littlefield publishers.

Jardin, André (1988): Alexis de Tocqueville 1805-1859, Méjico, Fondo de Cultura Económica.

Keane, John (1992): Democracia y sociedad civil, Madrid, Alianza.

Lamberti, Jean Claude (1970): La Notion d'individualisme chez Tocqueville, $\mathrm{Pa}$ ris, PUF.

Lamberti, Jean Claude (1983): Tocqueville et les deux démocraties, París, PUF.

Lawler, Peter (1992): "The human condition: Tocqueville's debt to Rousseau and Pascal", en E. Nolla (ed.), Liberty, equality, democracy, New York, New York University Press. 
Manent, Pierre (1991): "Intérêt privé, intérêt public", W.AA., L'Actualité de Tocqueville, Caen, Centre de Publications de l'Université de Caen.

Mayer, John (1965): Alexis de Tocqueville, estudio biográfico de ciencia política, Madrid, Tecnos.

Nolla, Eduardo (1989): Estudio introductorio, traducción y notas de la edición crítica de La Democracia en América de Tocqueville, Madrid, Aguilar.

Ortega y Gasset, José (1971): "Tocqueville y su tiempo", en Obras Completas, t. ${ }^{9}$, Madrid, Revista de Occidente.
Renaut, Alain (1993): La era del individuo, contribución a una historia de la subjetividad, Barcelona, Destino.

Renaut, Alain (1999): El futuro de la ética, Barcelona, Galaxia Gutenberg-Círculo de Lectores.

Ros, Juan Manuel (2001): Los dilemas de la democracia liberal: sociedad civil y democracia en Tocqueville, Barcelona, Crítica.

Sauca, José María (1995): La ciencia de la asociación en Tocqueville: presupuestos metodológicos para una teoría liberal de la vertebración social,
Madrid, Centro de Estudios Constitucionales.

Schleifer, James (1984): Cómo nació la democracia en América de Tocqueville, Méjico, Fondo de Cultura Económica.

Tocqueville, Alexis de (1989): La democracia en América, tomos 1 y 2, Madrid, Aguilar.

Tocqueville, Alexis de (1954): Oeuvres Complètes, VI, 1, Paris, Gallimard.

Tocqueville, Alexis de (1981): El antiguo régimen y la revolución, I, Madrid, Alianza.

Touraine, Alain (1994): ¿Qué es la democracia?, Madrid, Temas de Hoy. 